\title{
ARTICLES
}

\section{Virtual Reality}

\author{
A Survey of Use at an Academic Library
}

Megan Frost, Michael Goates, Sarah Cheng, and Jed Johnston

\section{ABSTRACT}

We conducted a survey to inform the expansion of a virtual reality (VR) service in our library. The survey assessed user experience, demographics, academic interests in VR, and methods of discovery. Currently our institution offers one HTC VIVE VR system that can be reserved and used by patrons within the library, but we would like to expand the service to meet the interests and needs of our patrons. We found use among all measured demographics and sufficient patron interest for us to justify expansion of our current services. The data resulting from this survey and the subsequent focus groups can be used to inform other academic libraries exploring or developing similar VR services.

\section{INTRODUCTION}

Virtual reality (VR) is commonly defined as an experience in which a user remains physically within their real world while entering a virtual world (comprising three-dimensional objects) using a headset with a computer or a mobile device. ${ }^{1} \mathrm{VR}$ is part of a spectrum of related technologies ranging from mostly real experiences to completely virtual experiences, such as augmented reality, augmented virtuality, and mixed reality. ${ }^{2}$ Extended reality (XR) is a term often used when describing these technologies as a whole.

Many different XR devices and services are available in academic libraries. The most popular XR devices used in libraries are the HTC VIVE, the Oculus Rift by Facebook, and Google Cardboard. ${ }^{3}$ Other common XR devices include GearVR by Samsung and PlayStation Virtual Reality by Sony. ${ }^{4}$ The HTC VIVE and Oculus Rift are technologies that provide an immersive virtual-reality experience. Google Cardboard provides both non-immersive virtual reality and augmented reality experiences, while mixed reality is provided through various technologies such as Microsoft's HoloLens and mixed-reality headsets from HP, Acer, and Magic Leap. In addition, many academic libraries are using augmented reality apps that can be downloaded on patrons' personal mobile devices. ${ }^{5}$

Academic libraries are starting to offer various XR services to increase engagement with patrons and teach information literacy. ${ }^{6}$ Despite the increase in XR service offerings, there is little consistency in the devices used or in how these services are developed at academic libraries, and there is substantial variation in the types of services offered. For example, some libraries make VR headsets available for in-house activities, such as storytelling, virtual travel, virtual gaming, and the development of new skills. ${ }^{7}$ Other libraries, notably Ryerson University Library and Archives in Toronto, let students and faculty borrow their Oculus Rift headsets for two or three days at a time. ${ }^{8}$ Some university libraries lend out headsets or 360-degree cameras or provide a virtual-

Megan Frost (megan@byu.edu) Physiological Sciences Librarian, Brigham Young University. Michael Goates (michael_goates@byu.edu) Life Sciences Librarian, Brigham Young University. Sarah Cheng is an undergraduate student, Brigham Young University. Jed Johnston (jed_johnston@byu.edu) Innovation Lab Manager, Brigham Young University. 
reality space for students to develop content. ${ }^{9}$ The University of Utah Library offers an open-door, drop-in VR workshop once a week. ${ }^{10}$ Claude Moore Health Sciences Library at the University of Virginia implemented a project that educated its students and staff on the uses of VR in the health field through a combination of large-group demonstrations, one-on-one consultations, and workshops. $^{11}$

The XR field is developing quickly, and XR services have the potential to benefit students academically. Some universities are already offering classes on VR platforms. ${ }^{12}$ This is particularly true in fields that are high risk or potentially discomforting. For example, students in medical fields benefit by practicing virtually before attempting surgery on a human body. ${ }^{13}$ In addition to potential surgical benefits, the University of New England has been utilizing XR technology to teach empathy to its medical and other health profession students by putting the learner in the place of their patients. ${ }^{14}$ Other examples of XR usage in the health fields include a recent attempt to introduce VR in anatomic pathology education and the use of virtual operating rooms to train nurses and educate the public. ${ }^{15}$ One recent study measured the effectiveness of using VR platforms in engineering education and found a drastic improvement in student performance. ${ }^{16}$

Many educational institutions outside of the university setting have also started exploring how XR could be used to enhance students' educational experience. This technology has already progressed from being considered a novelty to being an established tool to engage learners. ${ }^{17}$ One of the perceived benefits of XR use in public libraries by both library patrons and staff is the ability of XR technology to inspire curiosity and a desire to learn. ${ }^{18}$ In some school programs, students are able to advance their learning through XR apps that allow them not only to absorb information but also to experience what they are learning through hands-on activities and full immersion without danger (e.g., hazardous science experiments) or high cost (e.g., traveling to another country). ${ }^{19} \mathrm{XR}$ has the potential to increase the overall engagement of students, which, according to Carnini, Kuh, and Klein's 2006 study, is correlated to how well students learn. ${ }^{20}$

XR has the ability to capture the attention of students and eliminate distractions. This is particularly true for students with attention deficit disorder, anxiety disorders, or impulse-control disorder. ${ }^{21}$ The application of XR goes beyond traditional classroom settings. A case study assessing the benefits of VR in American football training found that players showed an overall improvement of 30 percent after experiencing game plays created by their coaches in a virtual environment. ${ }^{22}$ Although these studies were not conducted in an academic library or university setting, their results are transferable. It is beneficial to academic libraries to provide technologies to their patrons that enhance and advance their learning.

Currently, XR apps available for purchase on the Google App Store are still limited. Most app development comes from private companies; however, some universities are giving their students the opportunity to develop XR content. ${ }^{23}$

\section{OBJECTIVES}

At Brigham Young University, we want our VR services to foster the link between academic achievement and virtual reality. In order to do this effectively, our first objective is to determine which VR services will be of most benefit to our patrons. To inform the expansion of future VR services, we conducted a survey of patrons using current VR services in the library. This survey is also intended to help other libraries that are developing VR services and potentially developers 
interested in creating academic content for students. We were primarily interested in user experience, demographics, academic interests in VR, and methods of discovery.

\section{METHODS}

During one semester, January through April 2018, we asked individuals to complete a questionnaire following their use of the library's HTC VIVE system. This questionnaire was administered through an online Qualtrics survey that was distributed via email to patrons after using the library's VR equipment. It consisted of thirteen questions that gathered basic demographic information as well as information on patron interests and experiences with the library's VR services. The complete survey used in this study can be found in Appendix A.

Currently the Harold B. Lee Library at Brigham Young University offers one HTC VIVE VR system that can be used on site in the science and engineering area of the library. It is primarily operated by student employees who work at the science and engineering reference desk. Time slots are reserved through an online registration system on the library's website.

In order to gather more in-depth, qualitative data on patron experience with the library's VR services, we also conducted a focus group with VR users. We recruited participants by adding a question at the end of the Qualtrics survey asking whether the responder would be interested in participating in a focus group. All focus group participants received a complimentary lunch. During the focus group, we asked a series of five questions to gain a deeper understanding of users' VR experience at the library. In particular, we asked participants to explain what went well during their VR experience in the library, what difficulties they experienced, how they envisioned using VR for both academic and extracurricular purposes, and what type of VR content (e.g., software or equipment) they would like the library to acquire. The focus group facilitator asked follow-up questions for clarification as needed. The session was audio recorded, and participant responses were transcribed and coded for themes.

\section{RESULTS AND DISCUSSION}

\section{Demographics}

The most frequent users of the VR equipment in the library were male students in the science. technology. engineering, or mathematics (STEM) disciplines. The percentage of male students at Brigham Young University is roughly 50 percent but over 70 percent of our survey respondents were male. That stated, there was considerable use among all measured demographics, as shown in figure 1. Over one third of responders were not students. University faculty made up 11 percent of responders during the survey period. The proportion of faculty who responded was higher than the university's faculty-to-student ratio and likely the result of directly advertising the service to non-student university employees. Because some users informed librarians that they had brought spouses and children to use the equipment, we estimate that the 7 percent of responders who were neither students nor university employees mostly consisted of family or friends accompanying students or employees. Over one third of student responders were majoring in disciplines outside of science, technology, engineering, and mathematics. This number is small when compared to the number of students in these majors across campus (approximately 63 percent of students on campus are not majoring in STEM disciplines.); however, it demonstrates that there is an interest in VR technology throughout the university. As the VR services are located in the science and engineering area of the library, it is not surprising that more students majoring 
in these disciplines used these services when compared to students majoring in other disciplines. In fact, 15 percent of responders learned about the services at the reference desk, where they could see other patrons using the VR equipment. The most common discovery method, however, was the various forms of advertisements targeted to both students and employees of the Brigham Young University, as shown in figure 2.

Gender

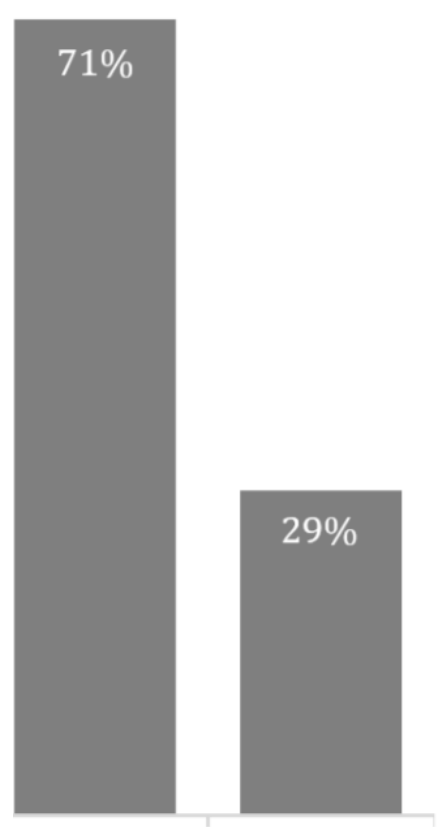

Male

\begin{abstract}
Female
\end{abstract}
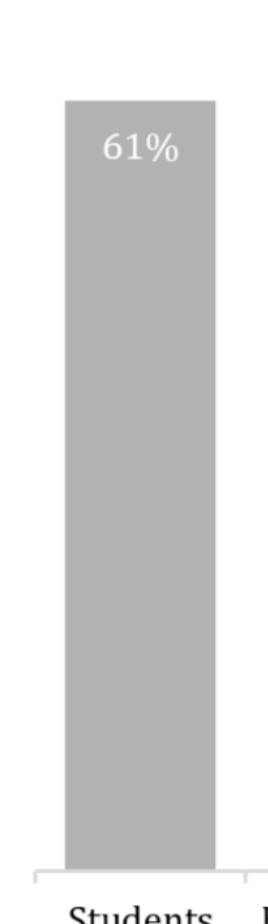

Students
Status

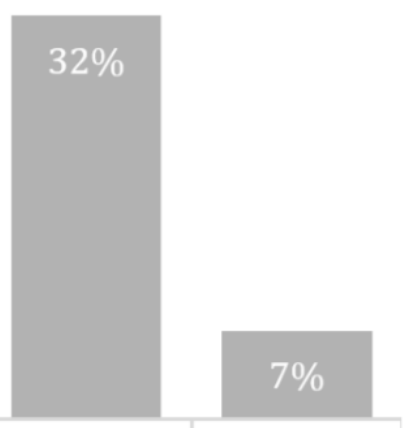

Employees

Other

Figure 1. Demographics.

Student

Discipline

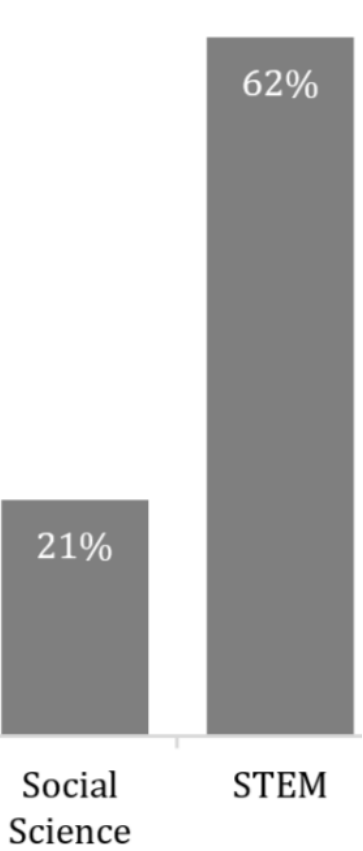




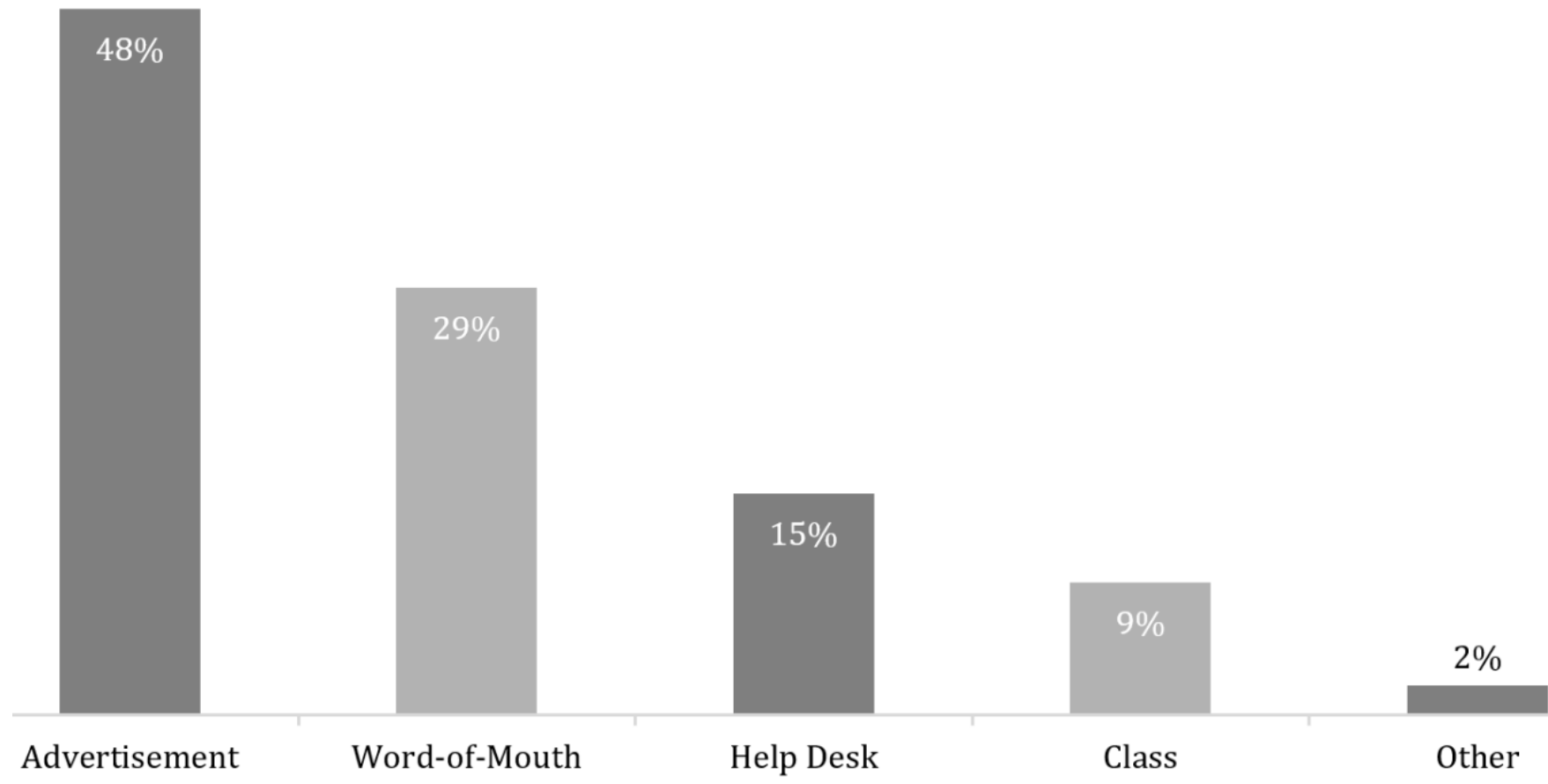

Figure 2. Most effective discovery methods: advertisement and word-of-mouth.

Only 7 percent of responders identified research or class assignments as their primary reason for using the services. The large majority of use, as shown in figure 3, was simply for entertainment or fun. This was not unexpected, especially as most of the users were trying the technology for the first time (see figure 4). However, because we purchased the equipment with the intent to support academic pursuits on campus, we hoped to see a higher percentage of academic use.

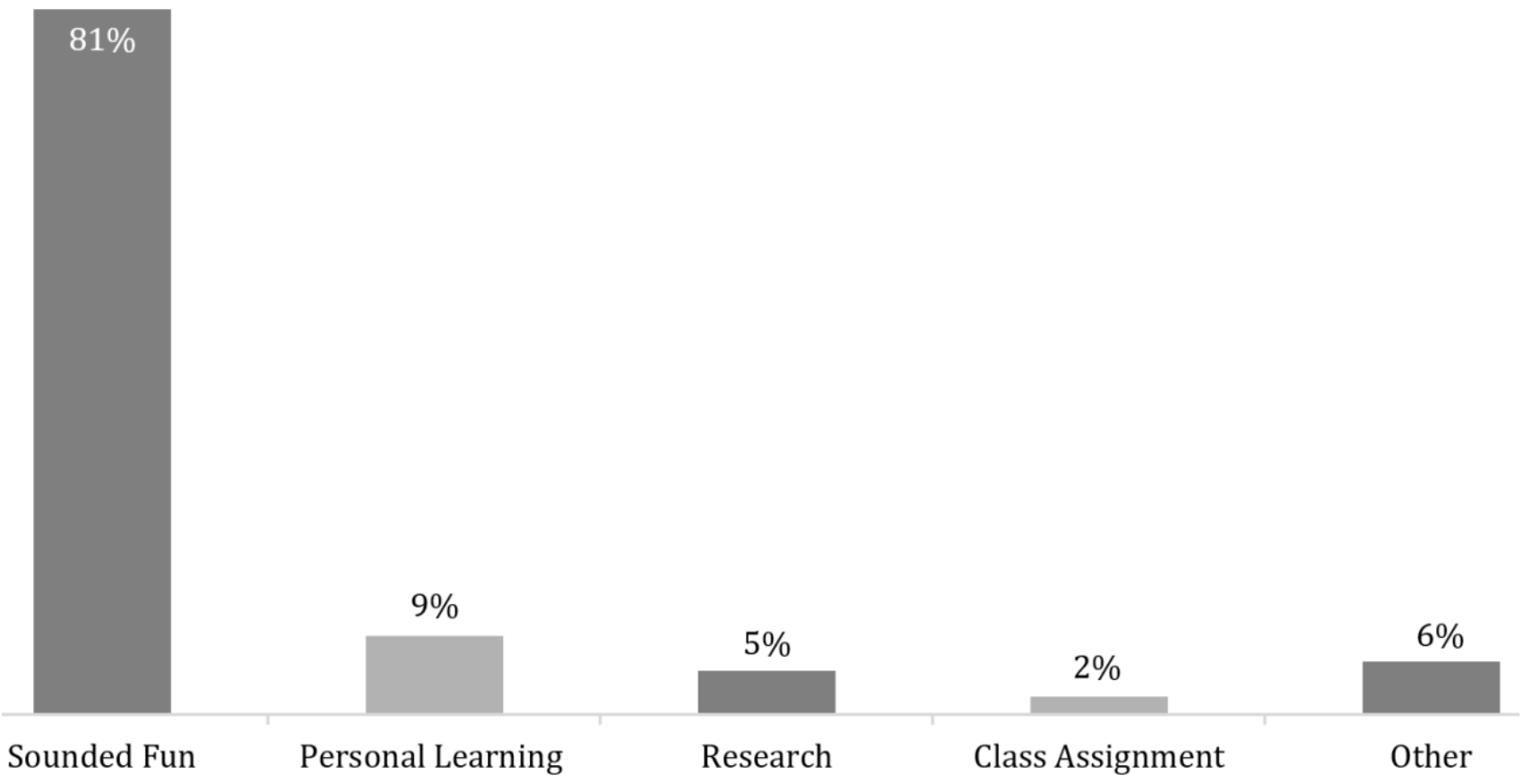

Figure 3. Most responders came because it sounded fun. 


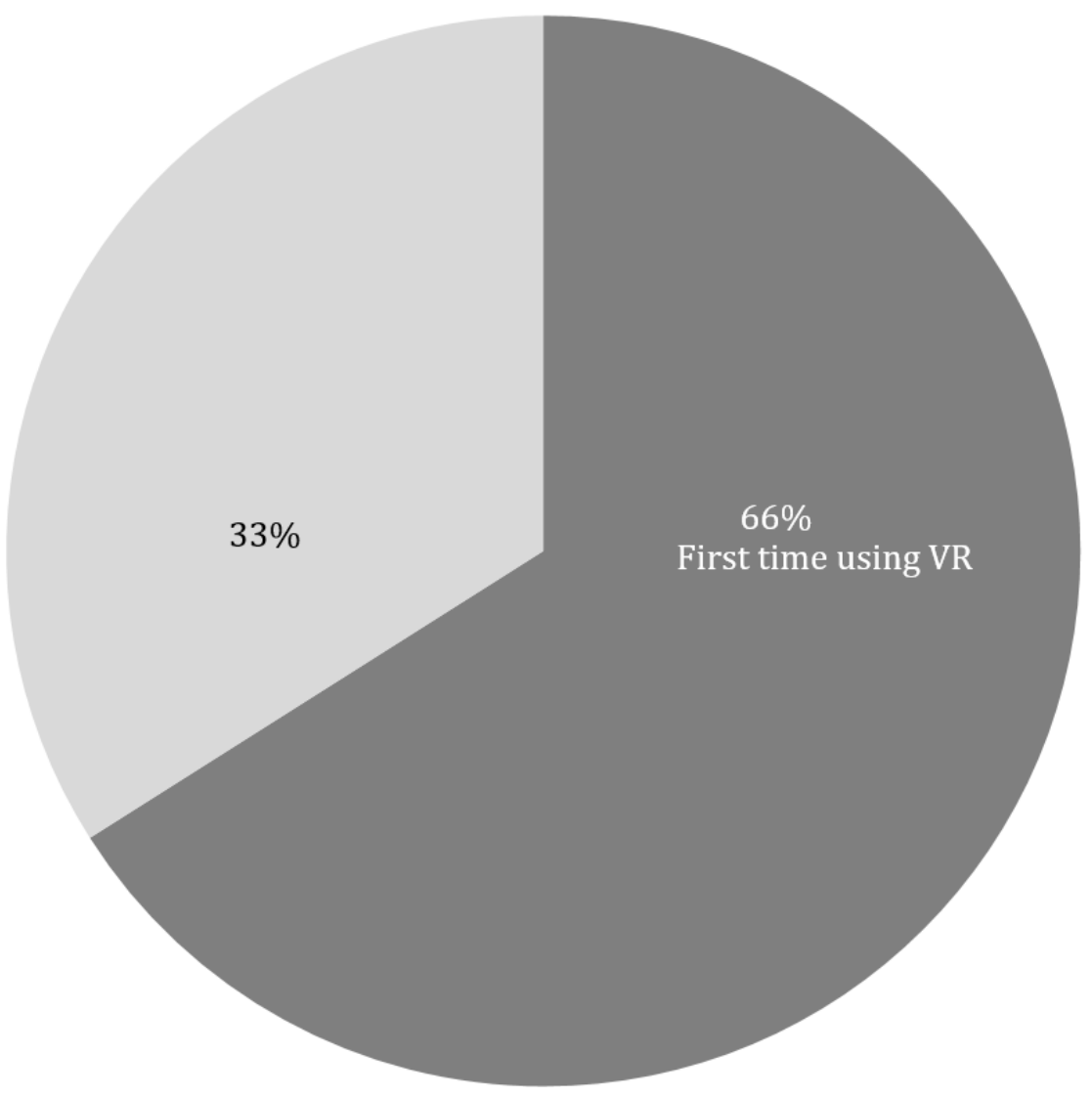

Figure 4. Most responders were first-time users.

Faculty use was higher than expected (see figure 5). Eleven percent of users during our survey period were faculty. The majority of these responders indicated an interest in potentially using VR technology with their students (see figure 6). While this interest was positive, faculty member suggestions for classroom use remained hypothetical, without any concrete intentions for implementation. This suggests that although faculty interest exists, faculty may need to be informed of specific application ideas in order to be more likely to incorporate this technology into their courses. 


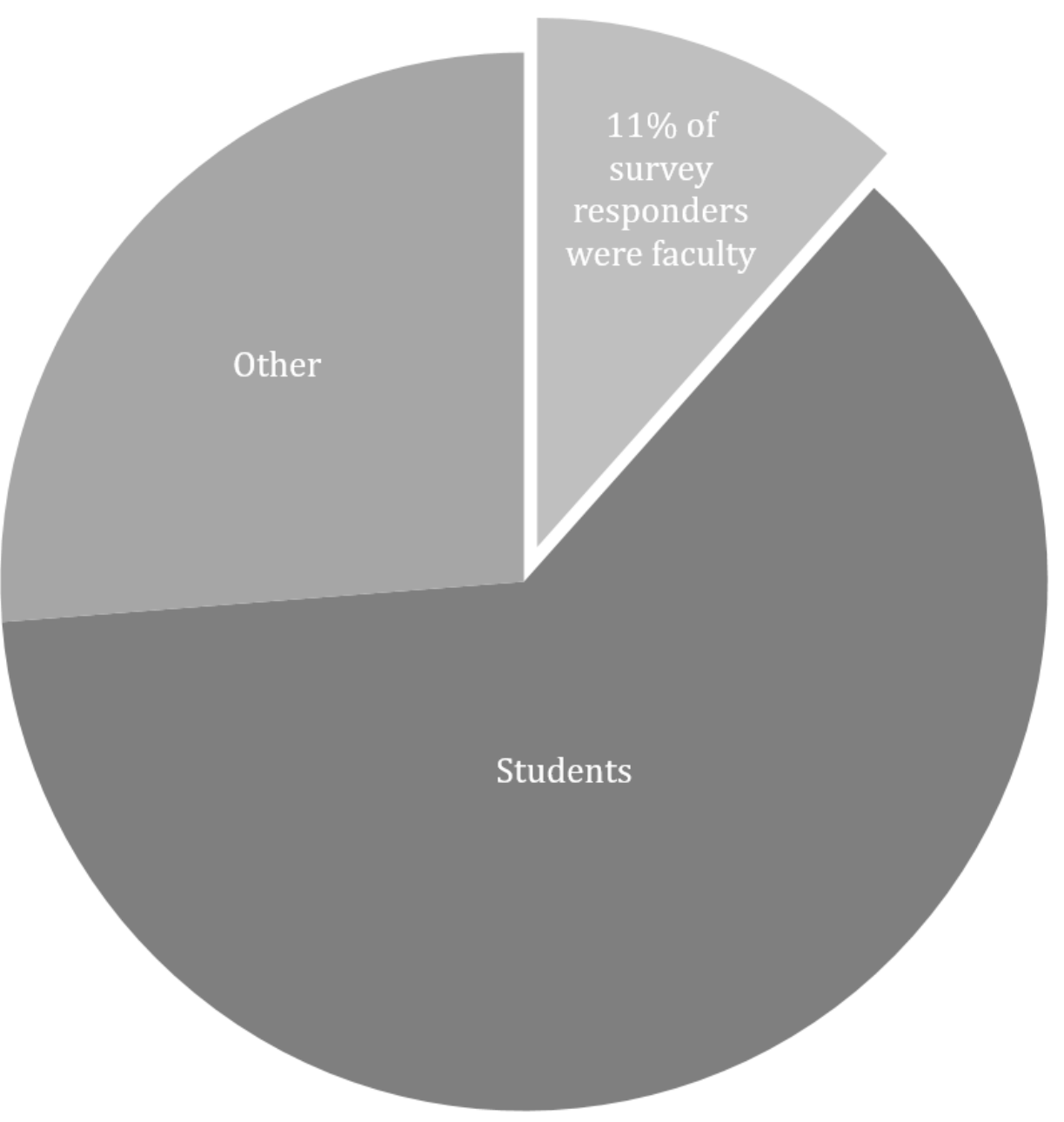

Figure 5. Faculty were interested in trying the VR equipment. 


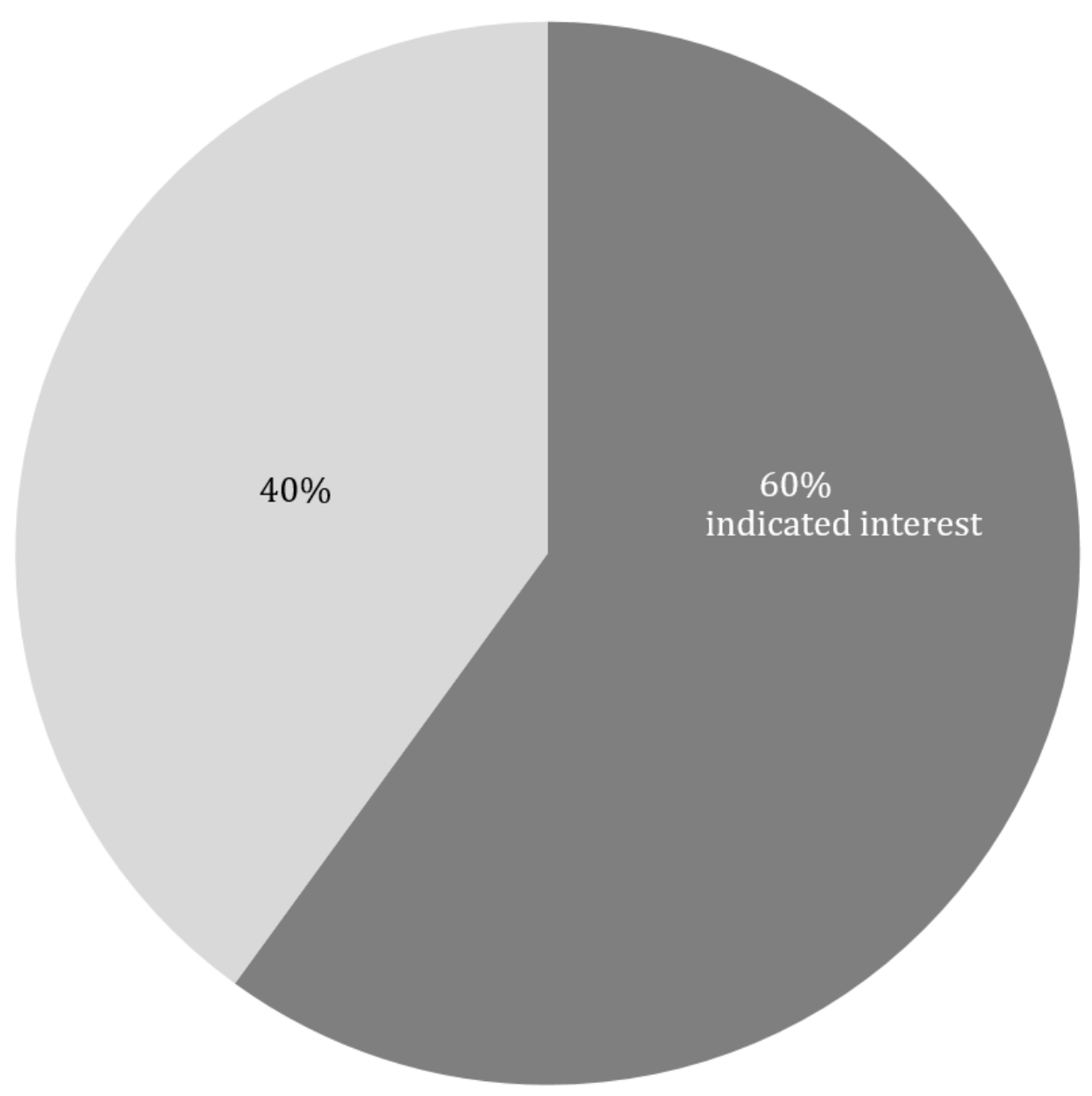

Figure 6. Faculty were interested in using VR academically.

A clear majority (72 percent) indicated an intention of returning to the library to use the service again (see figure 7). 
Definitely yes

Might or might not $5 \%$

Probably not $2 \%$

Definitely not

Probably yes
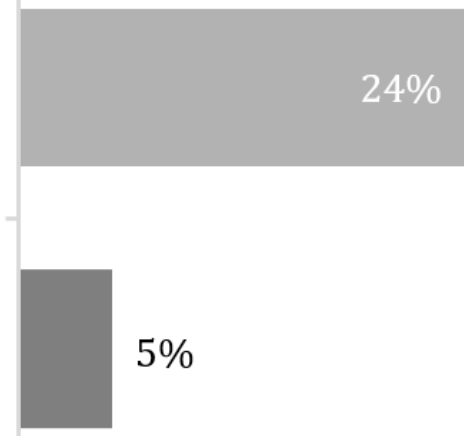

Figure 7. Most responders intend to return.

Because our VR services were a small pilot program at the time of the survey, we did not offer a large number of paid apps to users. Table 1 displays the most common apps used by survey responders. Most users tried Google Earth during their session, and employees at the reference desk often recommended this app to new users. Another common app for new users was The Lab, which includes a few small games showcasing the current capabilities of VR. Google Tiltbrush is an app for creating 3D art. Virtual Jerusalem is an app that was created by faculty at Brigham Young University and allows users to walk around and explore the Jerusalem Temple Mount during the time of Christ. The fifth-most-used app we offered was 3D Organon VR Anatomy, which teaches human anatomy.

1. Google Earth

2. The Lab

3. Tiltbrush by Google

4. Virtual Jerusalem

5. 3D Organon VR Anatomy

Table 1. Top five apps used.

\section{Focus Group Data}

We conducted a total of three focus group sessions. Each session included between five and eight participants, for a total of twenty-one focus group participants. Because we were primarily 
interested in student responses, we limited focus group participants to students enrolled at Brigham Young University. The participants were asked to describe what did or did not go well during their VR session. When describing what went well during their VR session, many participants responded with positive comments about the quality of service the library employees provided during their session. Most participants expressed satisfaction with the number and quality of the apps provided by the library. During all three focus groups, participants mentioned that they liked how easy it was to sign up for the VR services. The most common problems reported by participants related to health or safety concerns, such as feeling dizzy, bumping into objects in the room because of the lack of space, and tripping over the headset wire. Others reported problems related to the level of personal or social comfort with the VR services, such as feeling self-conscious using VR in a semi-open space not exclusively devoted to VR services or being told to be quieter.

When asked about ways the library could improve its VR services, the students suggested solutions to many of these problems. A frequent recommendation was that the library dedicate a space to VR. The reasons for this suggestion included minimizing the risk of accidentally bumping into objects, reducing the embarrassment of using the VR equipment in front of spectators, and allowing participants to become more fully immersed in the VR experience without worrying about being too loud. Other common suggestions included providing more than one headset for multiple patrons to use for gaming purposes or team projects, acquiring wireless headsets to eliminate wire tripping hazards, and providing more online training videos to reduce reliance on library workers for common troubleshooting problems. Participants did not provide actionable suggestions on ways to decrease dizziness while operating VR equipment.

When asked about how the students could see themselves using VR academically, many responded with some of the more well-known uses of VR technology, such as potential uses in science, medicine, engineering, and the military. However, some students had a very hard time determining how VR could be applied to humanities fields such as English. After some discussion, most students were able to see the relevance of VR in their field, but some said that they most likely would not pursue those functions of VR, using VR exclusively for extracurricular activities.

In contrast to the lack of academic uses envisioned by focus group participants, participants had substantially more ideas about how they would use VR for extracurricular purposes, including playing games for stress relief, exercising, exploring the world, and watching movies. Many expressed interest in using VR for extracurricular learning outside their majors, such as virtually being part of significant historic events, exploring ecosystems, and visiting museums or other significant landmarks. Students expressed interest in exploring the many possibilities provided by VR technology but were not especially aware of or interested in how VR might apply to their specific field of study unless they were in an engineering, medical, or other science-related discipline.

\section{CONCLUSIONS}

VR is a rapidly growing field, and academic libraries are already providing students access to this technology. In our study, we found considerable interest across campus in using VR in the library, however the academic interest and use were not as high as we hoped. Future marketing to faculty might benefit from specifically suggesting ideas for academic uses or collaboration. Even though our current VR services are located at the science and engineering help desk, nearly 40 percent of 
users were not in STEM disciplines. This is encouraging and suggests value in marketing future VR services to all library patrons. We also found sufficient patron interest to justify exploring related VR services, such as offering classes on creating content and acquiring less expensive headsets that can be borrowed outside of the library. Although this survey was limited to one university, we believe the results can be used to inform other academic libraries as they develop similar VR services.

\section{ENDNOTES}

${ }^{1}$ Susan Lessick and Michelle Kraft, "Facing Reality: The Growth of Virtual Reality and Health Sciences Libraries," Journal of the Medical Library Association: JMLA 105, no. 4 (2017): 407.

2 Paul Milgram et al., "Augmented Reality: A Class of Displays on the Reality-Virtuality Continuum," in Telemanipulator and Telepresence Technologies 2351 (International Society for Optics and Photonics, 1995), 282-92.

${ }^{3}$ Hannah Pope, “Incorporating Virtual and Augmented Reality in Libraries,” Library Technology Reports 54, no. 6 (2018): 8.

${ }^{4}$ Sarah Howard, Kevin Serpanchy, and Kim Lewin, "Virtual Reality Content for Higher Education Curriculum," Proceedings of VALA (Melbourne, Australia: Libraries, Technology and the Future Inc., 2018), 2.

${ }^{5}$ Zois Koukopoulos and Dimitrios Koukopoulos, "Usage Scenarios and Evaluation of Augmented Reality and Social Services for Libraries," in Digital Heritage. Progress in Cultural Heritage: Documentation, Preservation, and Protection (Springer International, 2018), 134-41; Leanna Fry Balci, "Using Augmented Reality to Engage Students in the Library," Information Today Europe/ILI365 (November 17, 2017), https://www.infotoday.eu/Articles/Editorial/FeaturedArticles/Using-Augmented-Reality-to-engage-students-in-the-library-121763.aspx.

${ }^{6}$ Bruce Massis, "Using Virtual and Augmented Reality in the Library," New Library World 116, nos. 11-12 (2015): 789, https://doi.org/10.1108/NLW-08-2015-0054.

${ }^{7}$ Adetoun A Oyelude, "Virtual and Augmented Reality in Libraries and the Education Sector," Library Hi Tech News 34, no. 4 (2017): 3, https://doi.org/10.1108/LHTN-04-2017-0019.

${ }^{8}$ Weina Wang, Kelly Kimberley, and Fangmin Wang, "Meeting the Needs of Post-Millennial: Lending Hot Devices Enables Innovative Library Services," Computers in Libraries (April 2017): 7.

9 “Oxford LibGuides: Virtual Reality: Borrowing VR Equipment,” Bodleian Libraries, https://ox.libguides.com/vr/borrowing; "Virtual Reality Services," Penn State University Libraries, https://libraries.psu.edu/services/virtual-reality-services; "VR Studio," North Carolina State, https://www.lib.ncsu.edu/spaces/vr-studio.

10 Oyelude, "Virtual and Augmented Reality," 3.

${ }^{11}$ Lessick and Kraft, "Facing Reality: The Growth of Virtual Reality," 409. 
12 Oyelude, "Virtual and Augmented Reality," 3.

${ }^{13}$ Medhat Alaker, Greg R. Wynn, and Tan Arulampalam, "Virtual Reality Training in Laparoscopic Surgery: A Systematic Review \& Meta-Analysis," International Journal of Surgery 29 (2016): 86, https://doi.org/10.1016/j.ijsu.2016.03.034.

${ }^{14}$ Elizabeth Dyer, Barbara J. Swartzlander, and Marilyn R. Gugliucci, "Using Virtual Reality in Medical Education to Teach Empathy," Journal of the Medical Library Association: JMLA 106, no. 4 (2018): 498, https://doi.org/10.5195/jmla.2018.518.

15 Emilio Madrigal, Shyam Prajapati, and Juan Hernandez-Prera, "Introducing a Virtual Reality Experience in Anatomic Pathology Education," American Journal of Clinical Pathology 146, no. 4 (2016): 462, https://doi.org/10.1093/ajcp/aqw133; Nils Fredrik Kleven et al., "Training Nurses and Educating the Public Using a Virtual Operating Room with Oculus Rift," IEEE (2014): 1, https://doi.org/10.1109/VSMM.2014.7136687.

${ }^{16}$ Wadee Alhalabi, “Virtual Reality Systems Enhance Students' Achievements in Engineering Education," Behaviour \& Information Technology 35, no. 11 (2016): 925, https://doi.org/10.1080/0144929X.2016.1212931.

${ }^{17}$ Patricia Brown, "How to Transform Your Classroom with Augmented Reality-EdSurge News," Edsurge, November 2, 2015, https://www.edsurge.com/news/2015-11-02-how-to-transformyour-classroom-with-augmented-reality.

${ }^{18}$ Negin Dahya et al., "Virtual Reality in Public Libraries," University of Washington Information School, https://ischool.uw.edu/vrinlibraries.

${ }^{19}$ Del Siegle, "Seeing is Believing: Using Virtual and Augmented Reality to Enhance Student Learning," Gifted Child Today 42, no. 1 (2019): 46, https://doi.org/10.1177/1076217518804854.

${ }^{20}$ Guillaume Loup et al., "Immersion and Persistence: Improving Learners' Engagement in Authentic Learning Situations," 11th European Conference on Technical Enhanced Learning (2016): 414, https://doi.org/10.1007/978-3-319-45153-4_35; Robert Carini, George Kuh, and Stephen Klein, "Student Engagement and Student Learning: Testing the Linkages," Research in Higher Education 47, no. 1 (2006): 23-4, https://doi.org/10.1007/s11162-005-8150-9.

${ }^{21}$ Mariano Alcaniz, Elena Olmos-Raya, and Luis Abad, "Use of Virtual Reality for Neurodevelopmental Disorders: A Review of the State of the Art and Future Agenda," MedicinaBuenos Aires 79, nos. 77-81 (2019): 419-20, https://doi.org/10.21565/ozelegitimdergisi.448322.

22 Yazhou Huang, Lloyd Churches, and Brendan Reilly, "A Case Study on Virtual Reality American Football Training," Proceedings of the 2015 Virtual Reality International Conference 6 (2015): 3, https://doi.org/10.1145/2806173.2806178.

23 "Media Lab," Massachusetts Institute of Technology, https://libraries.psu.edu/services/virtualreality-services; "The iSchool Technology Resources at FSU: Virtual Reality," Florida State University LibGuides, https://guides.lib.fsu.edu/iSchoolTech/VR. 